\title{
Exploring a refined model of home literacy activities and associations with children's emergent literacy skills
}

\author{
Eke Krijnen ${ }^{1}\left[\right.$ - Roel van Steensel ${ }^{1,2} \cdot$ Marieke Meeuwisse $^{1} \cdot$ Joran Jongerling $^{1} \cdot$ \\ Sabine Severiens ${ }^{1}$
}

Published online: 24 May 2019

(c) The Author(s) 2019

\begin{abstract}
Based on the Home Literacy Model, this study explored a refined model of home literacy activities and their relations with children's emergent literacy skills in a linguistic and socio-economic diverse sample of 214 Dutch kindergartners (mean age 4 years and 7 months, $46 \%$ girls and 29\% monolingual speakers of Dutch). The study examined a typology of home literacy activities that explicitly addressed didactic approach and was not restricted to activities involving print. Next, the study explored the relations between activity types and children's emergent literacy skills. Three activity categories were identified: code, oral language exposure and oral language teaching activities. Results of multilevel structural equation modeling showed that all types of home literacy activities were related to children's oral language skills, although the association between oral language teaching and oral language skills was negative. Oral language skills were associated with children's code and phonological skills. The outcomes indicate the existence of a more nuanced pattern of interrelations between elements of the home literacy environment and children's literacy skills in this diverse sample than observed before.
\end{abstract}

Keywords Family literacy $\cdot$ Home literacy environment $\cdot$ Emergent literacy $\cdot$ Direct teaching $\cdot$ Oral language $\cdot$ Code skills

Eke Krijnen

krijnen@essb.eur.nl

1 Erasmus School of Social and Behavioural Sciences, Erasmus University Rotterdam, P.O. Box 1738, 3000 DR Rotterdam, The Netherlands

2 Faculty of Humanities, Language, Literature and Communication, VU University Amsterdam, De Boelelaan 1105, 1081 HV Amsterdam, The Netherlands 


\section{Introduction}

The importance of the home literacy environment for the emergent literacy development of young children has been well-documented (cf. Burgess, Hecht, \& Lonigan, 2002; Niklas \& Schneider, 2013). A frequently used framework to describe the home literacy environment and its relations with children's emergent literacy is the Home Literacy Model (HLM; Sénéchal, 2006; Sénéchal \& LeFevre, 2002, 2014). The HLM focuses on parent-child interactions with print only, whereas a wider array of activities may need to be included for a full understanding of how parent-child interactions contribute to different aspects of children's literacy development. Additionally, the Home Literacy Model does not explicitly consider the function of didactic approach adopted in the activities: the extent to which parents directly teach their children about language and print or playfully expose their children to language and print. Furthermore, the HLM has been investigated in diverse settings and populations, but to date, it has not been studied in the context of urban parts of the Netherlands. This context, in which the current study is situated, is characterized by a highly diverse population regarding home languages and educational background. Against this background, the purpose of this study was to explore a refined model of home literacy activities and their relations with children's emergent literacy skills that considers a wider spectrum of home literacy activities and explicitly addresses didactic approach.

\section{The Home Literacy Model}

When parents frequently engage children in literacy activities, this positively affects their emergent literacy skills (Burgess et al., 2002; Niklas \& Schneider, 2013). Emergent literacy is often divided into two domains, oral language and code skills (Lonigan, Purpura, Wilson, Walker, \& Clancy-Menchetti, 2013; Sénéchal, LeFevre, Smith-Chant, \& Colton, 2001). Oral language skills encompass all skills necessary to process the meaning of spoken and, eventually, written language, such as vocabulary knowledge, narrative knowledge, listening and text comprehension. Code skills involve skills necessary to interpret the code of written language, such as letter knowledge and word reading. Some scholars view phonological skills, that is, children's abilities to recognize and manipulate different sounds in words (Anthony, Lonigan, Driscoll, Phillips, \& Burgess, 2003) as a part of code skills (Lonigan et al., 2013; Storch \& Whitehurst, 2002). Others consider phonological skills to be a distinct ability (Sénéchal et al., 2001). According to a developmental conceptualization of phonological skills, different phonological subskills varying in linguistic and cognitive complexity are acquired in different stages of development (Anthony et al., 2003). Auditory perception, children's ability to perceive and detect phonemic differences between words, is viewed as a distinct underlying phonological skill, foundational for more complex phonological awareness skills (Janssen, Segers, McQueen, \& Verhoeven, 2017; McBride-Chang, 1995). The various domains of emergent literacy development are developmental precursors of formal reading development: according to the simple view of reading (Hoover \& Gough, 1990), 
reading comprehension is determined by a person's comprehension skills (preceded by oral language skills in emergent literacy development) and decoding skills (preceded by early code skills).

A frequently used framework explaining the pathways along which home literacy activities contribute to specific domains of children's emergent literacy skills prior to formal literacy instruction in school is the Home Literacy Model (HLM; Sénéchal, 2006; Sénéchal \& LeFevre, 2002). The HLM distinguishes two types of parent-child activities around print: formal and informal literacy activities. In formal literacy activities, the attention of parents and children is directed solely to print itself, for example, when parents teach their children to name the letters of the alphabet. In informal literacy activities, the message the print contains, instead of print itself, is the focus of attention. A prototypical informal activity is shared reading. According to the HLM, formal and informal activities are differentially related to children's code and oral language skills. The frequency with which parents and their children engage in informal literacy activities is associated with children's oral language skills, while formal literacy activities are related to children's code skills. According to the model, an indirect relation exists between home activities and phonological awareness, as the effect of home activities on phonological awareness is mediated by oral language and code skills.

Since its introduction, the HLM has been well studied (for an overview, see Sénéchal, Whissel, \& Bildfell, 2017). Whereas a number of studies corroborated the model (cf. Hood, Conlon, \& Andrews, 2008; Manolitsis, Georgiou, \& Tziraki, 2013), other studies could not replicate the specific pathways from the two types of home activities to oral language and code skills (cf. Kalia \& Reese, 2009; Kim, 2009; Manolitsis, Georgiou, \& Parrila, 2011). Furthermore, no consensus exists on the interrelations between oral language, code skills, and phonological awareness. According to the HLM, oral language before Grade 1 contributes to early phonological awareness, but does not influence early code skills. In contrast, other researchers found a direct pathway from oral language to code skills in young children (Dickinson, McCabe, Anastasopoulos, Peisner-Feinberg, \& Poe, 2003; Kendeou, Van den Broek, White, \& Lynch, 2009; Stephenson, Parrila, Georgiou, \& Kirby, 2008). These researchers stress the importance of oral language skills in any learning process, as children need these skills to learn from more experienced others.

\section{The HLM across contexts}

Studies into aspects of the HLM differ in settings. Studies corroborating the HLM have been mostly conducted in families from higher socio-economic backgrounds in Anglo-Saxon countries speaking languages that are orthographically complex, such as English and French (Hood et al., 2008; Sénéchal, 2006; Sénéchal \& LeFevre 2002, 2014; Skwarchuk, Sowinski, \& LeFevre, 2014). Increasingly, the HLM is investigated in other populations, for instance in families from lower socio-economic backgrounds (Carroll, 2013; Sparks \& Reese, 2012) and in other parts of the world, such as China, Korea, India, Greece and Finland (Chen, Zhou, Zhao \& Davey, 2010; Kalia \& Reese, 2009; Kim, 2009; Manolitsis et al., 2011, 
2013; Silinskas, Leppänen, Aunola, Parrila, \& Nurmi, 2010; Silinskas et al. 2012, 2013). Languages spoken in the samples differ in orthographic depth, from complex orthographical languages such as Chinese and English (Chen et al., 2010; Carroll, 2013; Kalia \& Reese, 2009; Sparks \& Reese, 2012) to languages with transparent orthographies, such as Korean, Greek, and Finnish (Kim, 2009, Manolitsis et al., 2011, 2013; Silinskas et al., 2010, 2012, 2013). The studies report mixed results. Some confirm the HLM (Chen et al., 2010; Manolitsis et al., 2013), while others do not or only partly (Carroll, 2013; Kalia \& Reese, 2009; Kim, 2009; Manolitsis et al., 2011; Silinskas et al., 2010, 2012, 2013; Sparks \& Reese, 2012). The specific pathways from home activities to oral language and code skills could not always be replicated: some scholars found that informal activities predicted both oral language and code skills (Kalia \& Reese, 2009), or only code skills (Sparks \& Reese, 2012). In other studies, the association between formal literacy activities and code skills was absent (Carroll, 2013) or negative (Kim, 2009; Silinskas et al., 2010, 2012, 2013). Direct negative pathways from formal literacy activities to children's phonological awareness have also been reported (Kim, 2009; Manolitsis et al., 2011). These mixed results indicate that socio-economic status and orthography are factors of importance.

The role of parental socio-economic status and parental education has been well established in the research literature. Parental socio-economic status and education have been found to influence the quality of the home literacy environment and consequently children's literacy development (Hart \& Risley, 1995; Hoff, 2006, 2013). Regarding orthography, research suggests that in opaque orthographies, the relationship between parent teaching about print and children's code skills is different from this relationship in transparent languages, some researchers reporting less strong relations between teaching and code skills in transparent orthographies (Manolitsis, Georgiou, Stephenson, \& Parrila, 2009; Manolitsis et al., 2011) and negative relations with phonological awareness (Kim, 2009; Manolitsis et al., 2011). These researchers suggest that parents expect children to acquire code skills in school, because they are relatively easy to master. Therefore, parents engage less in code teaching or only when they feel that their children lag behind in their code and phonological skills. Additionally, another factor of importance is children's linguistic background. Speaking a minority language at home may negatively influence children's performance in the majority language, due to lesser input in the majority language (Hoff, 2006, 2013; Scheele, Leseman, \& Mayo, 2010). However, being exposed to a rich home literacy environment in their mother tongue (the minority language) may be beneficial for children's emergent literacy development in the minority as well as the majority language (Cárdenas-Hagan, Carslon, \& PollardDurodola, 2007; Dixon, 2011; Scheele, Leseman, \& Mayo, 2010).

Despite the differences in contexts, most studies into the HLM examine relatively homogenous groups. Limited knowledge is available on whether the HLM holds in diverse samples regarding educational and linguistic family backgrounds. To date, the HLM has not yet been investigated in the context of urban parts of the Netherlands. This context is characterized by a highly diverse population regarding migration background, home language, and educational level. In the Netherlands, Dutch is the majority language and the language of instruction at school. Dutch has 
a relatively consistent orthography compared to English, but more complex than for example Greek and Finnish.

\section{Examining the formal-informal distinction in the Home Literacy Model}

Besides the contextual differences of studies into the HLM, methodological differences among these studies might explain the discrepancies in results, such as methods of analysis with respect to the inclusion of control variables, measurement of children's skills, and the operationalization of informal and formal literacy activities. The operationalization of informal and formal activities is further discussed in this section, as the definition and operationalization of the two activity types were the impetus for exploring a refined model of home literacy activities in this study.

Two aspects of the HLM's classification of home literacy activities into formal and informal activities are possibly problematic. First, the HLM is restricted to parent-child interactions with print. However, some researchers testing the model incorporate activities in their operationalizations of home literacy activities that do not involve print, for example teaching new words and definitions (Kalia \& Reese, 2009; Skwarchuk et al., 2014) and playing rhyming/singing games (Skwarchuk et al., 2014). One could argue that a broader interpretation of home literacy activities, also considering activities that do not involve print, might facilitate a more complete understanding of how children's home literacy experiences contribute to different aspects of their early literacy development. Similar to shared reading activities, other activities targeting oral language skills, such as storytelling and mealtime conversations, provide opportunities for children to use and listen to new words, narratives, and other forms of elaborate language, thereby likely contributing to children's oral language skills. Several studies have indeed shown that the quality of interaction during such activities and the frequency with which parents initiate them, stimulate the oral skills of young children (Curenton, Craig, \& Flanigan, 2008; Van Steensel, 2006; Weigel, Martin, \& Bennett, 2006). Additionally, activities focusing on sounds and rhymes, such as rhyming games and listening to nursery rhymes, which also do not involve print, have been related to children's code skills and phonological awareness (Levy, Gong, Hessels, Evans, \& Jared, 2006). Therefore, we propose a distinction between activities that support oral language and activities that target code skills, and assume that both categories can involve print as well as nonprint activities.

Second, the HLM does not directly consider didactic approach. Didactic approach can be regarded as a continuum with direct instruction activities, such as teaching the alphabet or teaching new words, on the one end. More child-centered, playful activities in which the child is exposed to language and print, such as talking with your child and playing (educational) games, are situated on the on the other end of the continuum (Hannon, 2000, 2003; Stipek, Milburn, Clements, \& Daniels, 1992). Some researchers suggest that didactic approach may be related to parental education, with lower educated parents more likely to engage in direct teaching and higher educated parents more likely to engage in exposure activities (Lynch, Anderson, Anderson, \& Shapiro, 2006; Stipek et al., 1992). Additionally, parents' 
cultural background and schooling experiences may determine their engagement in either teaching or exposure activities (Gillanders \& Jiménez, 2004; Reese, Arauz, \& Bazan, 2012; Reese \& Gallimore, 2000).

Although Sénéchal et al. (2017) explicitly mention that formal literacy activities can be playful, informative as well as didactic (p. 384), nearly all studies testing the model operationalize formal literacy as direct teaching activities only. Activities exposing children to print without directly teaching them, such as playing letter games, are not included. Since informal activities are often operationalized as shared reading-related activities only, the difference between formal and informal activities not only reflects a distinction between activities focusing on print and activities focusing on meaning, as proposed by Sénéchal et al. (2017; Sénéchal \& LeFevre, 2002). This difference also (maybe unintentionally) reflects a distinction in didactic approach, with activities adopting a teaching method on the one hand (formal literacy activities) and activities in which the child is playfully exposed to print (informal literacy activities) on the other hand. To consider didactic approach explicitly in a categorization of home literacy activities would enable researchers to determine whether observed relations between activity types and children's literacy skills are due to the content of the activity (focus on either code or meaning) or the way parents guide their children (teaching versus exposure).

\section{A refined typology of home literacy activities}

We propose an alternative conceptualization of home literacy activities, based on two distinctions. First, we distinguish activities that support oral language from those that target code skills, and assume that both categories can involve print as well as non-print activities. Second, we propose a distinction in didactic approach, namely teaching activities versus exposure activities. These two distinctions result in four hypothetical categories of home literacy activities: oral language exposure (including shared reading and listening to stories the child tells); code skills exposure (including playing letter games and rhyming); oral language teaching (including teaching new words and having your child repeat new words); and code skills teaching activities (including teaching the letters of the alphabet, practicing name writing) (see Fig. 1).

\section{Current study}

The aim of the current study was to explore the refined typology of home literacy activities and to analyze associations between activity categories and children's oral language, code and phonological skills in a highly diverse sample situated in urban parts of the Netherlands. Following the HLM, we expected that, should an exploratory factor analysis reveal categories such as defined in our refined model, those categories would be related to the skills they target, that is, oral language exposure and oral language teaching would be related to oral language skills and code exposure and code teaching would be associated with code skill. We hypothesized all activity 


\section{Teaching}

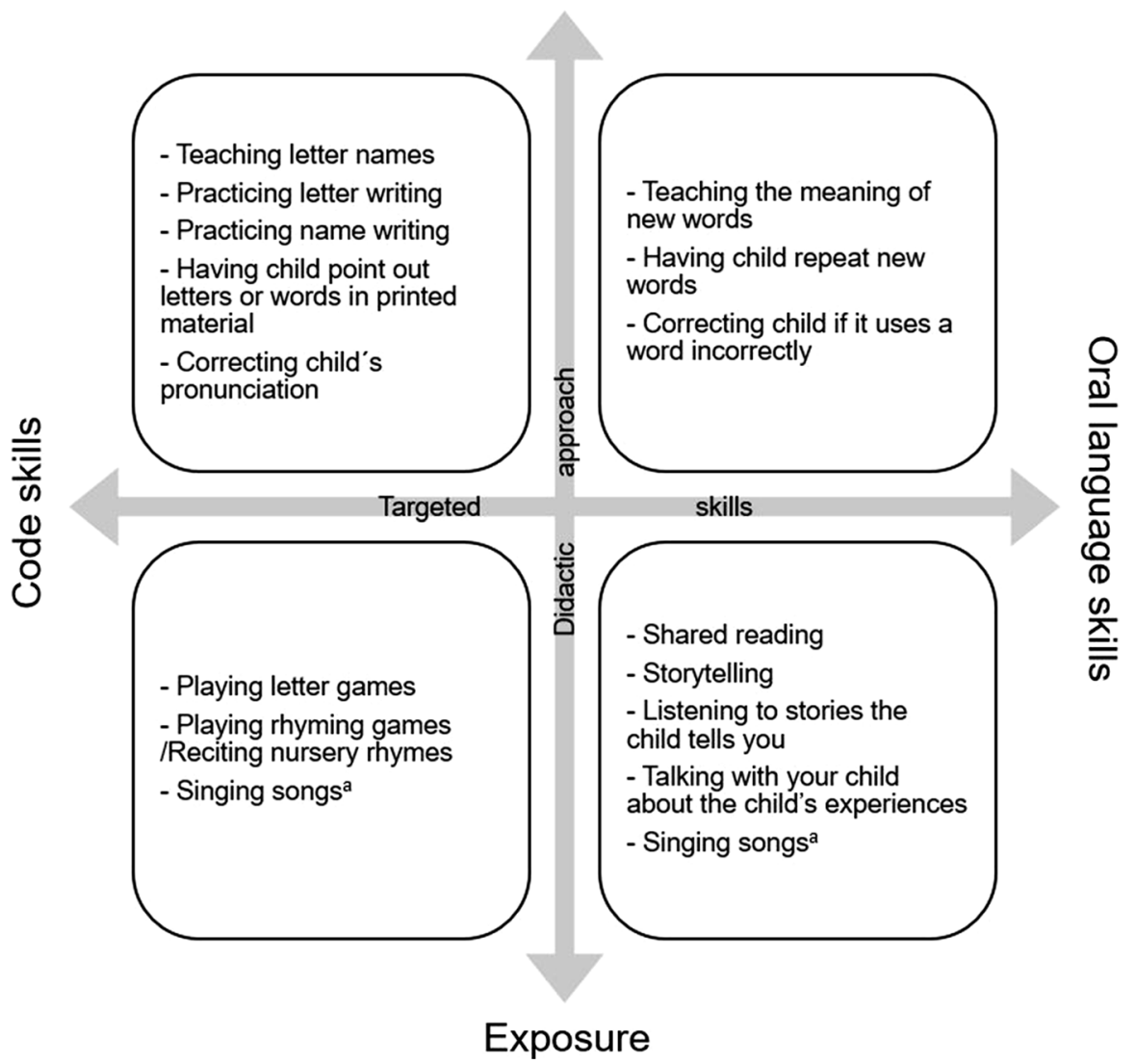

Fig. 1 Proposed conceptualization of home literacy activities

${ }^{a}$ Our expectations for the item 'singing songs' were twofold: singing songs could either be a code activity, targeting phonological awareness similar to rhyming activities, or it could be an oral language activity targeting vocabulary and narrative knowledge

types to be related to phonological skill indirectly, that is, mediated by either oral language skills or code skill. Figure 2 shows the initial model we explored.

\section{Methods}

\section{Context of the study}

This cross-sectional study was conducted as part of a larger study on the effects of a family literacy program. In the larger study, children were followed for 2 years, starting when they just entered kindergarten. The data reported here are based on the pre-test of that study. At that time, the children had only been exposed to formal 


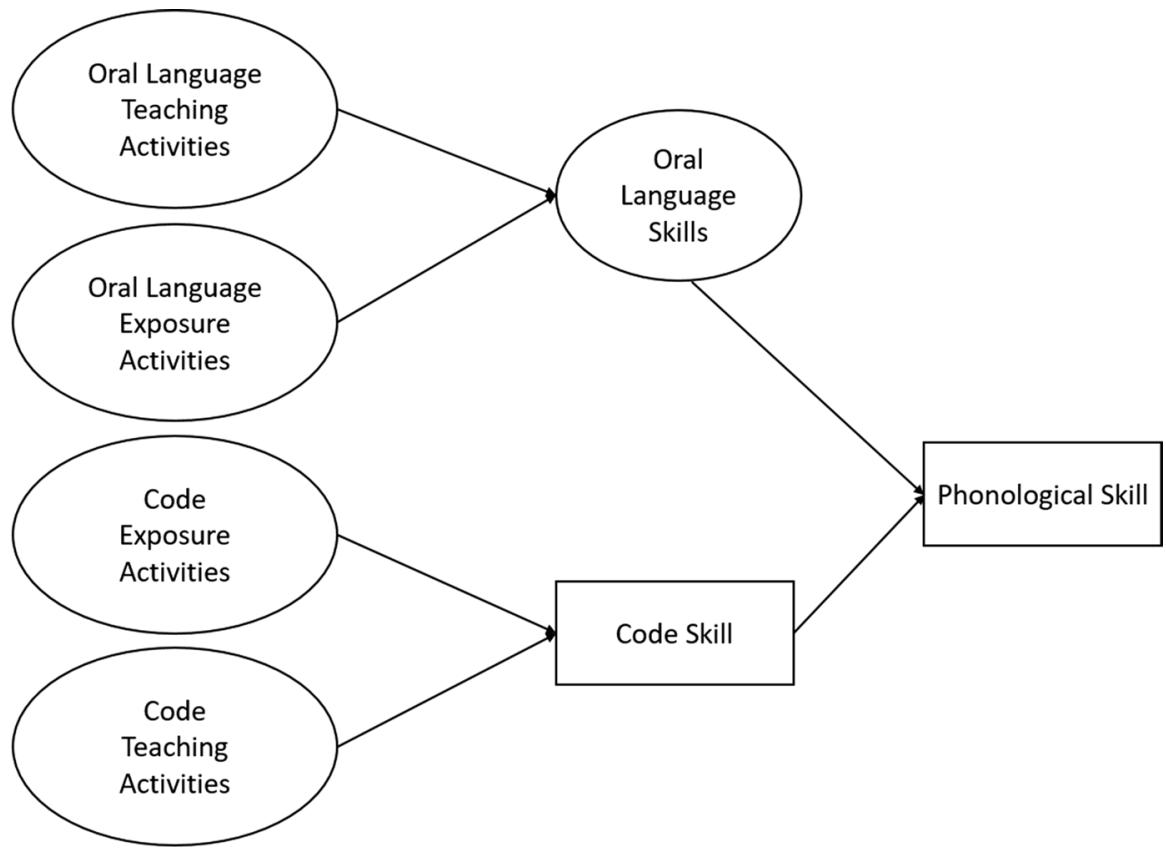

Fig. 2 Theoretical model describing relations to be explored between different types of home literacy activities and children's emergent literacy skills, based on the Home Literacy Model (Sénéchal, 2006; Sénéchal \& Lefevre, 2002)

schooling for a few weeks. Children in the Netherlands generally start in the first year in kindergarten at age four. The kindergarten curriculum explicitly targets the development of emergent literacy skills, which is reflected in the goals aspired for children at the end of their second year in kindergarten. According to this curriculum, children should know approximately 7000 (Dutch) words receptively and 3500 words productively, have acquired knowledge of the functions of print, are able to recognize and name an unspecified number of letters, are able to write symbols that resemble letters, know that letters correspond to sounds, and have mastered the Dutch phonological system, before entering Grade 1 (Stichting Leerplan Ontwikkeling, 2010).

\section{Participants}

Participants in this study were 214 children (age: 4-5 years). Parents of the children were invited to complete a parent questionnaire to provide demographic information. Hundred seventy-nine parents returned the questionnaires (response rate: 84\%), of which 142 were mothers and 34 were fathers; three respondents did not indicate their role. Twenty-nine percent of the sample spoke only Dutch at home. Forty percent of the sample spoke another language at home in addition to Dutch. Ten percent of the sample did not speak Dutch at home. For $21 \%$ of 
the children, their home language was unknown. Forty-three different languages were spoken with the children, Dutch being most frequently mentioned, followed by Turkish, Moroccan-Arabic, and Berber languages. Twenty-nine percent of the children had parents with low levels of education, $29 \%$ had parents who were middle educated, $21 \%$ of the children had high-educated parents. Parental educational level was unknown for $21 \%$ of the children. Educational level was evenly distributed across the different language groups. Of the parents who spoke both Dutch and (an)other language(s) with their children, 34\% was lower educated, $46 \%$ was middle educated and $20 \%$ was higher educated. Only in the group of parents who did not speak Dutch with their children, lower educational levels were overrepresented. Of this group, $67 \%$ was lower educated, $10 \%$ was middle educated and $23 \%$ was higher educated. The children were enrolled in 12 schools in the Netherlands, divided over 20 classes. For an overview of child and parent characteristics, see Table 1.

\section{Materials}

\section{Oral language}

Children's oral language skills were measured by testing children's receptive vocabulary knowledge and their narrative production skills. Vocabulary was measured using the Receptive Vocabulary Task from the validated Dutch test battery Taaltoets Alle Kinderen (TAK) [Language Test for All Children] (Verhoeven \& Vermeer, 2001, 2006). The task consists of 96 items. For each item, four pictures are shown to the child while the test administrator reads a word corresponding with one of the pictures. The child is asked to point at the picture representing the word. Difficulty level increases with every item. If a child fails to give the right answer five times successively, the administrator stops the test. A child's score is formed by the number of correct answers (Cronbach's $\alpha=.96$, current study).

Narrative production was measured by the Storytelling Task from the TAK. For this task, the child is shown two sheets with eight pictures, each sheet describing a short story. The child is asked to tell the story to the test administrator, in a way that she can understand the story without looking at the pictures. The narratives were audio-recorded and later transcribed and coded using a coding scheme consisting of 32 items on which children could score up to one point per item. Points are awarded on the basis of accuracy, coherence and cohesion of the story told, as depicted by the pictures. Coherence and accuracy of the story are represented by the expression of the necessary content words to understand the story. Coherence and cohesion of the text are the expression of conjunctions and juxtaposition of story elements, expressing the main relationships depicted in the story. The maximum number of points is 32 . Twenty-two percent of the narratives $(n=47)$ were coded independently by two coders, with $89 \%$ agreement between the coders (Cronbach's $\alpha=.86$ for the main coder, current study). Disagreements were discussed between the two coders until agreement was reached. 
Table 1 Characteristics of study participants

Characteristic

Frequency and percentage of total sample

Total sample

Children

Parents (number of questionnaires returned)

$N=214,100 \%$

Gender children

Female

$n=179,84 \%$

$n=214$

Male

Gender parents

Female (mothers)

$n=98,46 \%$

Male (fathers)

Age children (in months)

$n=116,54 \%$

$n=176,82 \%$

$n=142,66 \%$

$n=34,16 \%$

$n=214$

range $=45-66$

$M=52.8, S D=3.8$

Age parents (in years)

$n=167$

range $=22-51$

$M=34.8, S D=6.1$

Children's country of birth

$n=166,78 \%$

Netherlands

$n=154,72 \%$

Other

$n=12,6 \%$

$n=172,80 \%$

Parents' country of birth

$n=74,34 \%$

Netherlands

Other

$n=98,46 \%$

$n=169,79 \%$

Home language

Only other language(s) than Dutch spoken at home with child

$n=22,10 \%$

Dutch and other language(s) spoken at home with child

$n=85,40 \%$

Only Dutch spoken at home with child

$n=62,29 \%$

Parents' best language

Dutch

Dutch and other language(s)

$n=169,79 \%$

$n=62,29 \%$

$n=85,40 \%$

Only other language

Educational level parent (respondent)

$n=22,10 \%$

$n=170,79 \%$

Low $^{\text {a }}$

$n=63,29 \%$

Middle $^{b}$

$n=63,29 \%$

$\operatorname{High}^{\mathrm{c}}$

$n=44,21 \%$

$n=139,65 \%$

Educational level respondent's partner

$n=58,27 \%$

Low

$n=41,19 \%$

Middle ${ }^{\mathrm{b}}$

$n=40,19 \%$

$\operatorname{High}^{\mathrm{c}}$

${ }^{a}$ No education, primary and/or prevocational secondary education

${ }^{\mathrm{b}}$ Senior general secondary education or pre-university education, and/or secondary vocational education

${ }^{c}$ Higher professional education or university degree 


\section{Code skill}

Code skill was operationalized as letter-sound knowledge. Due to the young age of our sample and their limited school experiences, more advanced tests of Code Skills, such as word identification or spelling, were not appropriate. Children's letter-sound knowledge was assessed with the Letter Knowledge Task from the validated Dutch test battery Toetspakket Beginnende Geletterdheid [Test Battery Emergent Literacy] (Aarnoutse \& Verhagen, 2012). The test consists of 27 items. In each of the first 20 items, five lower case letters are shown to the child while the test administrator phonetically pronounces a letter sound that corresponds with one of the five letters. The child is asked to point out the letter corresponding with the letter sound. In the last seven items, the child is asked to point out letter combinations, expressing a diphthong frequently occurring in the Dutch language. The number of correct answers is the total score for this test (Cronbach's $\alpha=.73$, current study).

\section{Phonological skill}

Phonological skill was operationalized as auditory perception, measured with the Auditory Discrimination Task from the TAK. Due to the relative large share of L2-speakers of Dutch and the young age of our sample in combination with the participating schools being located in neighborhoods characterized by the presence of many low SES households (Sociaal Cultureel Planbureau, 2017), we expected to find relatively low levels of Dutch emergent literacy skills in our sample. Therefore, it seemed more appropriate to measure an underlying phonological skill for phonological awareness than using more advanced tests, such as elision, blending, or rhyming tasks. The Auditory Discrimination Task consists of 50 items. For each item, the test administrator reads two words that are either identical (for example cat-cat) or different by one phoneme (for example bell-ball). The child is asked to indicate if the two words are the same or different. The number of correct answers is the score for this task (Cronbach's $\alpha=.92$, current study).

\section{Parent questionnaire}

Parents filled out a survey in paper format.

Home literacy activities This scale consists of 15 items related to parent-child activities. Parents were asked to indicate on a scale from 1 (never) to 5 (daily or several times a day) the frequency with which they engaged in several home literacy activities. These activities could be performed in any language that was spoken in the home. The items included in the questionnaire are all home literacy activities shown in Fig. 1.

Parental education Parental education was operationalized as the mean score of the highest educational level obtained by the children's parents: low (no education, pri- 
mary and/or prevocational secondary education), middle (senior general secondary education or pre-university education, and/or secondary vocational education), high (higher professional education or university degree) (Statistics Netherlands, 2017).

Child's age Child's age was measured by asking parents to indicate the birth date of their child.

Home language Parents were asked what language(s) they spoke with their child. Parents indicated whether they spoke only Dutch, Dutch and (an)other language(s) or only (an)other language(s) at home with their child. In the analyses, we included home language as a dichotomous variable $(0=$ only Dutch spoken with the children at home, $1=$ (additional) other languages spoken at home with the children).

Child's gender Parents were asked to indicate the gender of their child $(0=$ boy, $1=$ girl).

\section{Procedure}

Schools were recruited by advertising on social media and contacting the municipalities of the four major cities of the Netherlands. Schools were screened based on the criteria relevant for the larger study, such as the accordance of the school's population with the target group of the intervention (children with lower educated parents and/or second language learners of Dutch). The participating schools selected one or two classes in kindergarten to take part in the study. At the beginning of the school year, parents of the children received a letter from the school with information regarding the project and an invitation to take part. Parents communicated to the child's teacher their decision whether or not to take part in the study.

Between September and early November 2015, all children were tested individually at school by the first author and five trained research assistants. One test a time (duration 2-15 min) was administered. In November 2015, parents received the parent questionnaire from their children's teachers and were asked to return it before the Christmas break. Parent questionnaires were provided in four different languages: Dutch, English, Turkish, and Polish. Teachers were instructed by the researchers to assist parents filling out the questionnaire, if needed, without influencing their answers. Additionally, a research assistant trained in the field of Dutch language teaching offered help to parents in filling out the questionnaire if needed.

\section{Analysis}

As our main research aim was exploratory, namely to examine the validity of our refined model, the home literacy activity-items were analyzed with exploratory factor analysis (EFA). Structural relations between activity types and children's literacy skills were examined using multilevel structural equation modeling (SEM) techniques. After defining our model, parental education, home language, children's 
age, and gender were included in the analyses as covariates, as these variables have shown to be factors influencing the nature of the home literacy environment, the children's literacy development, and the interrelations between them (Hart \& Risley, 1995; Hoff, 2013; Scheele, Leseman, \& Mayo, 2010).

Due to the nested nature of the data (pupils nested within classes), multilevel methods were applied, in which we followed the procedures described by Hox (2010). Before starting our SEM-analysis, we analyzed for all variables whether significant variance existed at Level 2, using the statistical software package HLM (Raudenbush, Bryk, Cheong, Congdon, \& Du Toit, 2016). This was the case for children's vocabulary, narrative production, phonological skill, and for three of the four covariates, namely home language, parental education, and children's age. This implies that multilevel analysis is necessary (Hox, 2010). Therefore, these variables were allowed to have variance on both Level 1 and Level 2 of our SEM-model. The hypotheses this study aims to explore are situated at Level 1 (pupils). Therefore, no structural relations were hypothesized at Level 2 (classes). However, the exploratory method of analysis applied in this study can still reveal structural relations at the second level, should they exist.

All the consequent analyses were performed with the statistical software package Mplus (Muthén \& Muthén, 2010). In the next step, the data were analyzed separately at the pupil level (Level 1) from the class level (Level 2), to obtain a preliminary structural equation model. This preliminary Level 1 model was obtained in three steps. First, we ran an EFA on the home literacy activity variables, with oblique rotation performed on the pooled within variance-covariance matrix. Next, the factors resulting from the EFA were entered in a structural model together with children's scores for receptive vocabulary, narrative production, phonological skill, and letter knowledge. Finally, modification indices were inspected and adjustments were made, provided these were supported by theory.

Next, the preliminary Level 1 model was extended to a multilevel model. The preliminary Level 1 model was fitted to the whole dataset, while allowing the variables with significant amounts of variance at Level 2 (phonological skill, vocabulary, and narrative production) to have variance at the class level, but no covariance. If this model, called the independence model, fits well, variance exists at the class level, but there are no structural relations of interest. If this model has inadequate fit, a structural model at Level 2 needs to be specified (Hox, 2010). After specification of this model, the final model was further refined, provided adjustments were supported by theory. Finally, to test whether the model would sustain after including covariates, home language, parental education, child's age, and gender were entered in the model at Level 1. In addition, home language, parental education, and child's age were allowed to have variance at Level 2, as previous analyses in HLM showed that these covariates had significant variance at Level 2.

Fits of the different SEM models were evaluated using the Chi Square test, the ratio $\chi^{2} / \mathrm{df}$, the Root Mean Square Error of Approximation (RMSEA), the Comparative Fit Index (CFI) and the Standardized Root Mean Square Residual (SRMR). Model fit was considered good when $\chi^{2} / \mathrm{df}<2$, RMSEA $\leq .08, \mathrm{CFI} \geq .95$, and SRMR $\leq .08$ (Hu \& Bentler, 1999; Kline, 2015; Schermelleh-Engel, Moosbrugger, $\&$ Müller, 2003). Chi square difference tests applying the Satorra-Bentler correction 
(Satorra \& Bentler, 2001) were used to assess whether model modifications significantly improved model fit.

Univariate skewness and kurtosis values indicated the existence of multivariate non-normality (Byrne, 2012), therefore we used Maximum Likelihood estimation with robust standard errors (MLR), which is robust for non-normality. Because 35 parents did not return the parent-questionnaire, and of the 179 parents who did return the questionnaire, some parents did not answer all questions, there are missing data in our sample. Additionally, scores for children who could not understand the test instruction (ranging from $n=2$ to 22 for the four child measures) due to their limited understanding of Dutch, were regarded as missing values. MLR-estimation uses full information maximum likelihood to treat missing values. This implies that cases with missing values need not be excluded from the analyses. Hence, all 214 cases were included (Hox, 2010).

\section{Results}

\section{Descriptive statistics and bivariate correlations}

Table 2 shows descriptive statistics and bivariate correlation coefficients for all variables except gender and home language: associations between these two dichotomous variables and the other variables are presented in Table 3. As displayed in Table 2, parents tended to undertake fewer activities targeting code-related literacy skills than activities targeting oral language skills. Additionally, variability in responses was larger on the code activity items, whereas for both oral language exposure and teaching, variability on most items was small, with standard deviations $<1$. Parents indicated parent-child conversations as the most frequently occurring activity. Activities targeting oral language skills through teaching also occurred frequently (averages were all $>4$ on a 5-point scale). Children's scores on all outcomes were generally low, in particular the scores on the letter-sound knowledge and narrative production task. However, large differences in scores existed among the children, as shown by the large standard deviations.

Correlations between home literacy activities and children's outcomes are relatively low. Significant correlations exist between vocabulary and three of the oral language activities (parent-child conversations, shared reading, and storytelling) and four of the code activities (teaching letter names, practicing letter writing, rhyming, and letter games). Narrative production only significantly correlated with three of the code activities (teaching letter names, practicing name writing, and rhyming). Phonological skill correlated significantly with two of the oral language activities (parent-child conversations and shared reading), while letter-sound knowledge correlated negatively with the teaching of new words. Child's age correlated positively with two code teaching activities (practicing name and letter writing), indicating that parents of older children were more likely to teach their children about print than parents of younger children. Child's age was positively and significantly correlated with three of the four child outcomes (vocabulary, narrative production, and phonological skill). Parental education correlated positively with two of the oral language 


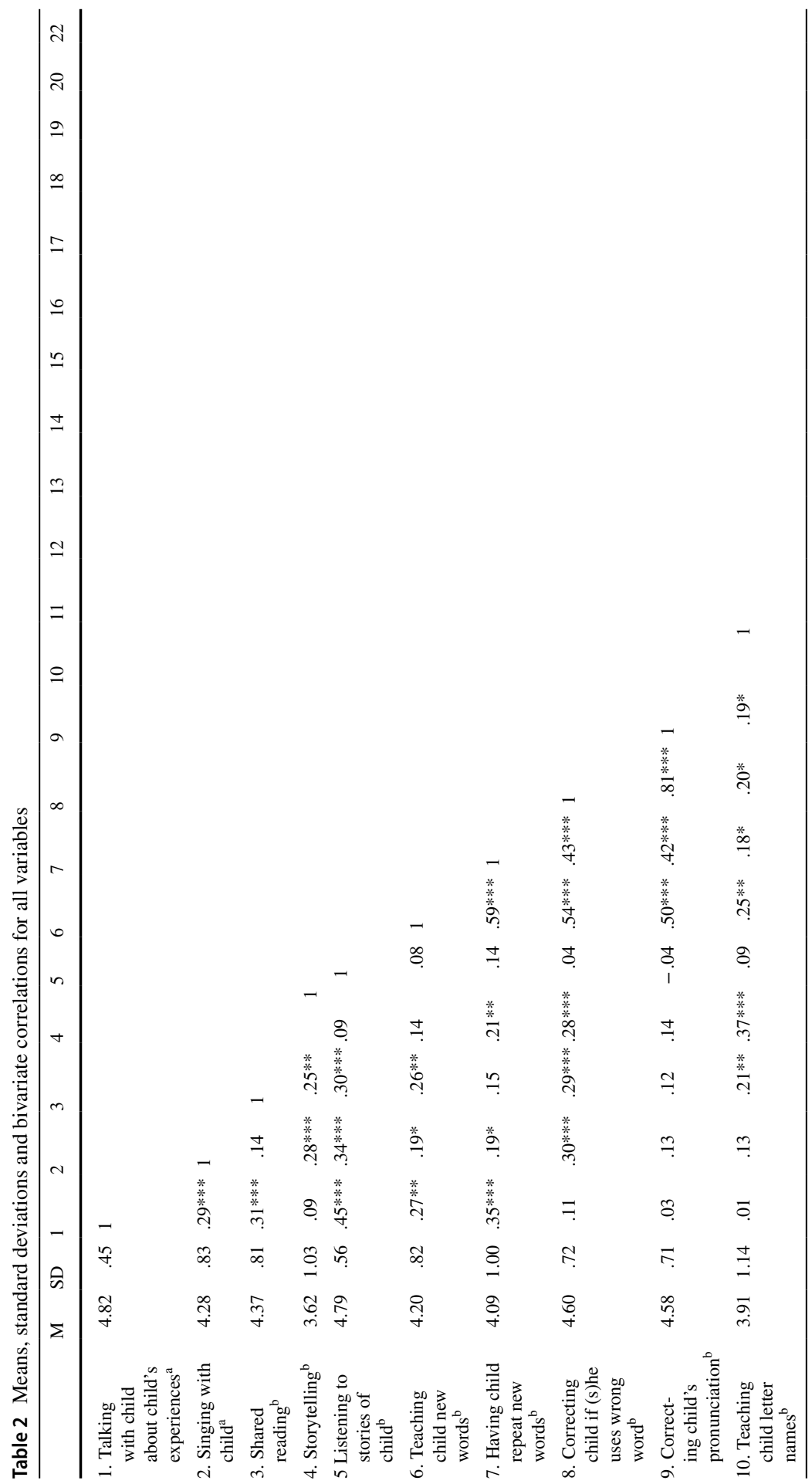




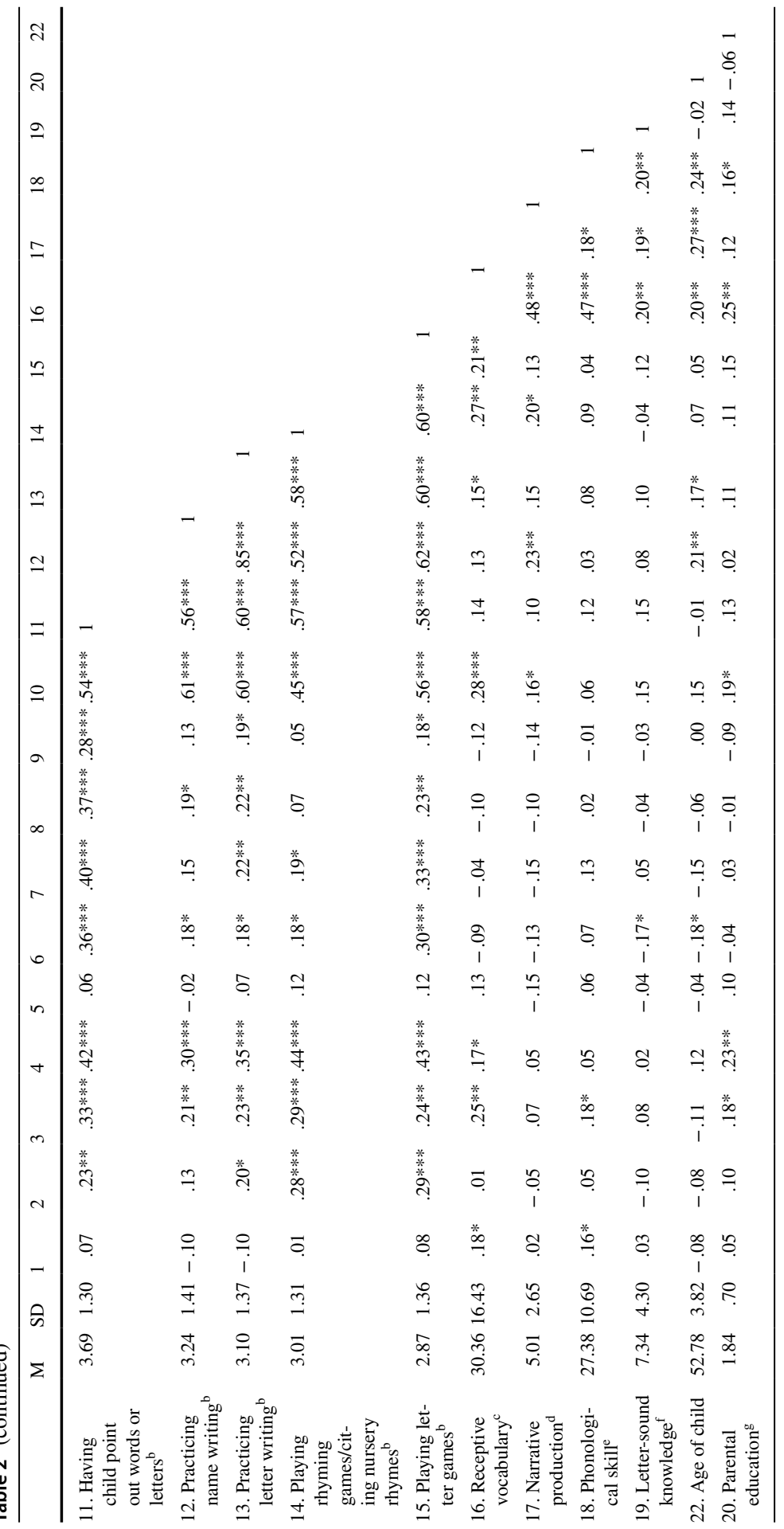




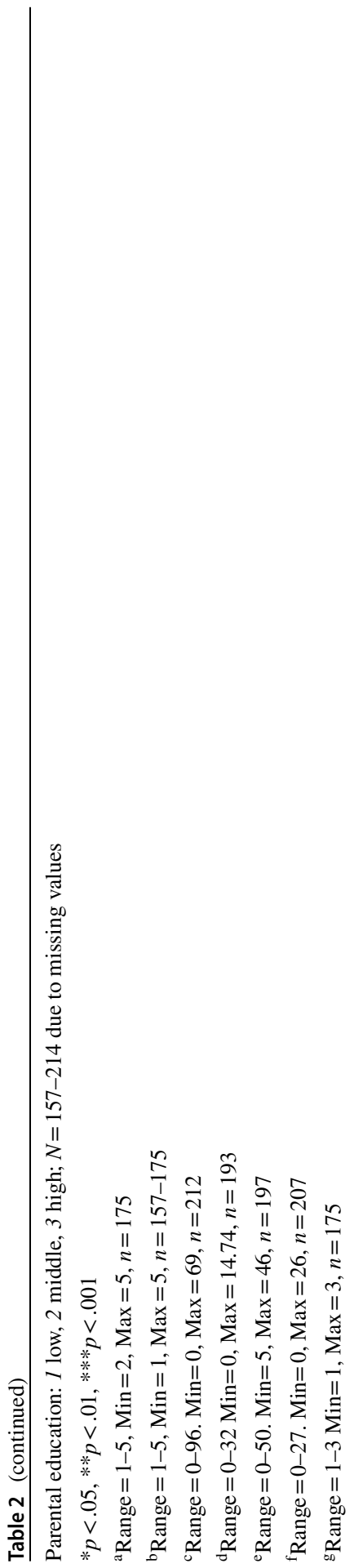




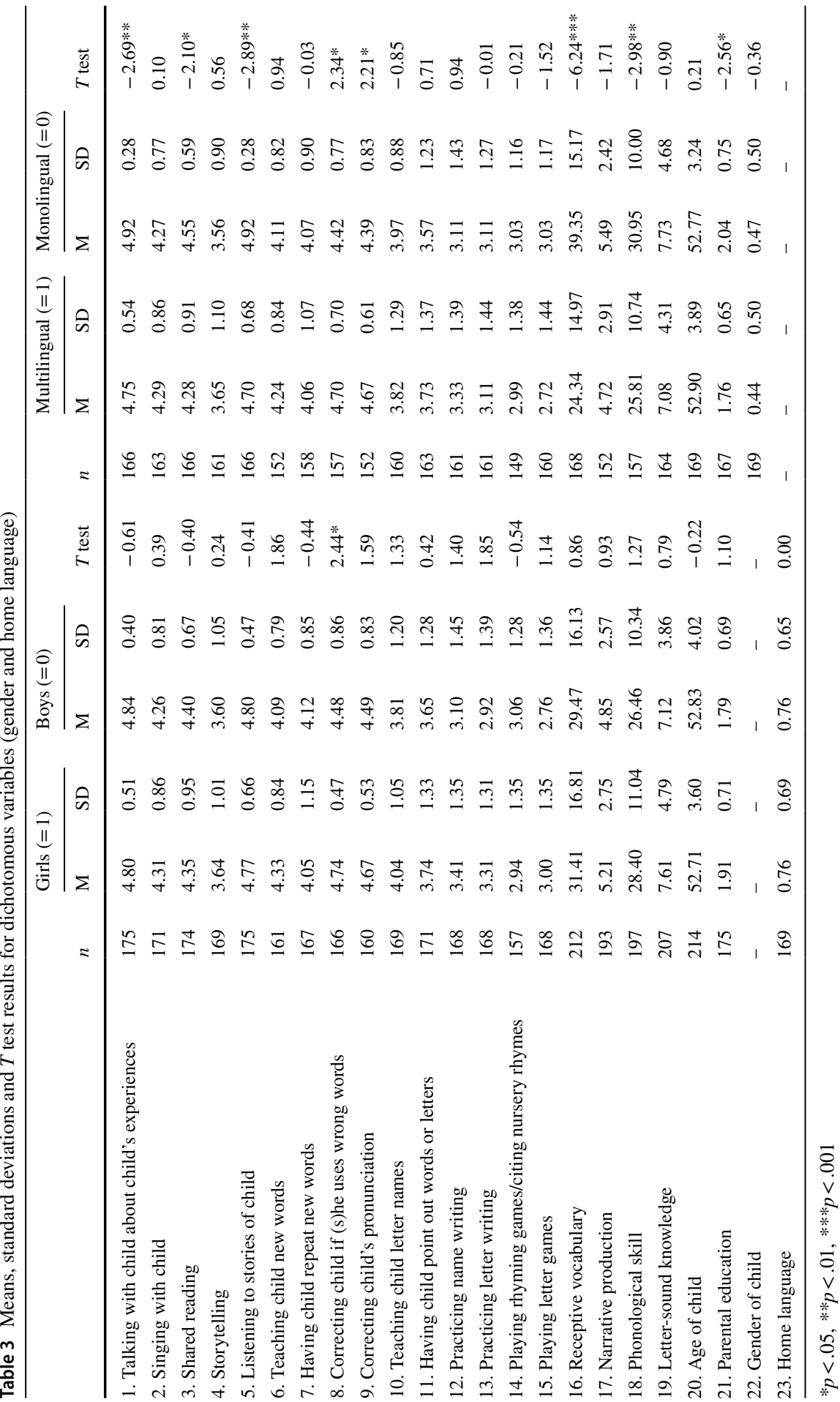


exposure items (shared reading and storytelling) and with one of the code teaching activities (teaching your child letter names) indicating that higher educated parents engaged more frequently in such activities. Parental education was also positively associated with phonological skill and vocabulary. There was only one difference in frequency of activities between girls and boys: girls' pronunciation was more likely to be corrected than boys'. There were differences between mono- and multilingual parents in five of the home literacy activities: scores were higher for monolingual parents on three of the oral language exposure activities (parent-child conversations, shared reading, and storytelling), whereas scores were higher for multilingual parents on two of the oral language teaching activities (correcting the use of wrong words and pronunciation). Additionally, there were differences between mono- and multilingual children in receptive vocabulary and phonological skill, in favor of the former, and there was an association between home language and parental education: monolingual parents generally had a higher education.

\section{Analyses at the first level: pupils}

\section{Exploration of validity of proposed conceptualization of home literacy activities}

The EFA on the home literacy activity items showed that a four-factor solution had a reasonable fit $\left(\chi^{2}[51, N=192]=126.05, p<.01 ; \chi^{2} / \mathrm{df}=2.47 ; \mathrm{CFI}=.943\right.$; RMSEA $=.088$, SRMR $=.039)$, but the item storytelling loaded significantly on three of the four factors. Consequently, the EFA was run again without this item. In the four-factor solution without the item storytelling, two factors consisted only of two items, which may indicate poor determinacy of the model (Brown, 2006). Additionally, the four-factor solution was not interpretable considering our theoretical assumption. As a result, we decided to fit a three-factor model.

A three-factor solution indicated that a distinction could be made between activities targeting oral language skills and activities targeting code-related skills. Furthermore, activities targeting oral language skills could be divided by didactic approach into teaching and exposure activities. The results did not show a distinction in coderelated activities based on didactic approach. As theoretical interpretability, complemented by statistical guidelines, should be leading in factor selection (Brown, 2006), we decided to work with the three-factor solution instead of the four-factor solution, despite of the lesser fit of the model $\left(\chi^{2}[52, N=192]=157.913, p<.01 ; \chi^{2} / \mathrm{df}=3.04\right.$; $\mathrm{CFI}=.916$; RMSEA $=.103$; SRMR $=.047)$. Table 4 shows factor loadings and reliability coefficients (Cronbach's $\alpha$ ) per factor. Factor 1 (items 1-4) was labelled Oral Language Exposure. Factor 2 (items 5-8) was labelled Oral Language Teaching, and Factor 3 (items 9-14) was labelled Code Activities.

In two cases, the item factor loadings need further explanation. First, the item 'correcting your child's pronunciation' did not load on Code Activities, as we expected. Instead, it loaded on Oral Language Teaching, possibly because pronunciation is regarded as an oral language skill, instead of a subskill of phonological awareness. Second, our expectations for the item 'singing songs' were twofold: singing songs could either be a code activity, targeting phonological awareness similar to 
Table 4 Factor loadings derived from the exploratory factor analysis of the parent-child home literacy activity scale (scores below 0.3 not shown) and reliability coefficients per factor (Cronbach's Alpha). The items of the factor scores displayed in bold type are included in the factor of the column in which the scores are positioned

\begin{tabular}{llll}
\hline Items home activity scale (1-5) & 1 & 2 & 3 \\
& $\begin{array}{l}\text { Oral language } \\
\text { exposure }\end{array}$ & $\begin{array}{l}\text { Oral language } \\
\text { teaching }\end{array}$ & Code \\
\hline
\end{tabular}

1. Talking with child about child's experiences

2. Singing with child

3. Shared reading

4. Listening to stories of child

5. Teaching child new words

6. Having child repeat new words

7. Correcting child if (s)he uses wrong word)

8. Correcting child's pronunciation

9. Teaching child letter names

10. Having child point out words or letters

11. Practicing name writing

12. Practicing letter writing

13. Playing rhyming games/citing nursery rhymes

14. Playing letter games

Cronbach's Alpha

\begin{tabular}{|c|c|c|}
\hline $.80 *$ & & \\
\hline $.33^{*}$ & & \\
\hline $.38 *$ & & \\
\hline $.58 *$ & & \\
\hline $.33 *$ & $.52 *$ & \\
\hline $.31 *$ & $.37 *$ & \\
\hline & $.92 *$ & \\
\hline & $.91 *$ & \\
\hline & & $.72 *$ \\
\hline & & $.64 *$ \\
\hline$-.34 *$ & & $1.00 *$ \\
\hline$-.33 *$ & & $1.01 *$ \\
\hline & & $.69 *$ \\
\hline & & $.73^{*}$ \\
\hline .61 & .82 & .89 \\
\hline
\end{tabular}

$* p<.05$

rhyming activities, or it could be an oral language exposure activity targeting vocabulary and narrative knowledge. According to the EFA results, the latter is the case.

\section{Structural relations between home literacy activities and emergent literacy skills}

Based on the results of the EFA, we adjusted our hypothesized model in Fig. 2. Instead of the expected four, three latent variables representing the different types of home literacy activities were entered in the model. In this adjusted model, the latent variables Oral Language Teaching and Oral Language Exposure were hypothesized to be associated with oral language and the latent variable Code Activities was assumed to be associated with code skill. This model fit the data poorly (see Table 5). The modification indices suggested adding a covariance between the residuals of two underlying items of Oral Language Teaching ('correcting words' and 'correcting pronunciation'), and between the residuals of two items of Code Activities ('practicing name writing' and 'practicing letter writing'), likely due to the overlap in content and wording between the items. Additionally, a pathway from Code Activities to Oral Language was suggested. An association between parent-child letter-based activities and children's oral language skills has been found by Haney and Hill (2004), justifying the addition of this pathway. These covariances and pathways 


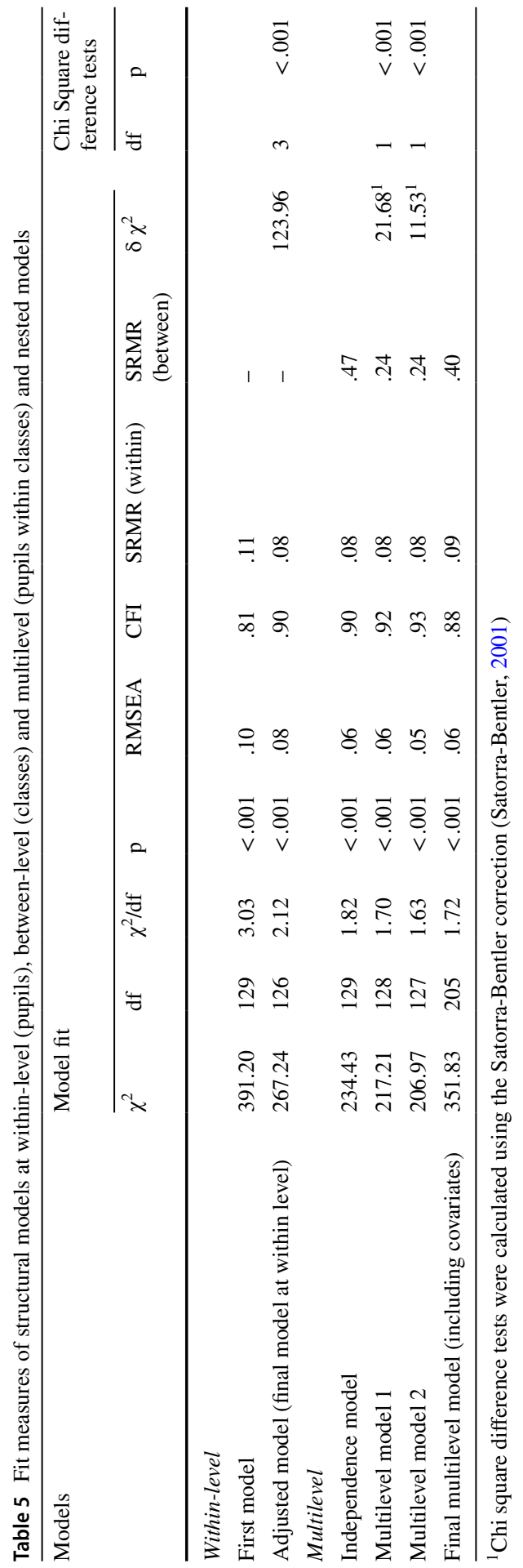


were added to the model, resulting in improved model fit (see Table 5). We settled on this model as our preliminary model at Level 1.

\section{Multilevel analyses}

The independence model fit the data poorly (as shown Table 5), implying that a structural model needed to be specified at the second level as well. The modification indices suggested a covariance at the second level between vocabulary and phonological skill, reflecting a relationship between vocabulary knowledge and phonological skill at the class level. This covariation may be a demographic effect. Our sample contained many second language learners, with likely lower vocabulary skills and phonological skills compared to their monolingual peers. Possibly, second language learners were clustered in classes and monolingual pupils were clustered in classes. To account for this relationship at the second level, we included this covariance in the model as our Level 2 model (named Multilevel Model 1). This step in the analysis resulted in a reasonable and significantly improved model fit (see Table 5).

The fit of the complete model could be further improved based on modification indices (Hox, 2010). At Level 1, the modification indices suggested adding a pathway from Oral Language to code skill (letter-sound knowledge). The relation between oral language skills and code-related literacy skills has been found in many previous studies (cf. Storch \& Whitehurst, 2002; Whitehurst \& Lonigan, 1998), justifying the addition of this pathway. The addition of this pathway resulted in a significantly improved model fit (see Table 5, Multilevel Model 2), although the pathways from Code Activities to code skill and from code skill to phonological skill lost their significance in this latest model. Finally, covariates were added to the model. Pathways were modeled between home language, parental education, child's age, and gender and the outcome variables oral language skills, code skill, and phonological skill. Home language, parental education, and child's age were allowed to have variance at Level 2. After the addition of the covariates, the model pathways remained unchanged, except for the pathway from letter-sound knowledge to phonological skill, which regained its significance. Home language was significantly negatively associated with Oral Language and age was significantly positively associated with phonological skill. No other significant associations existed between the covariates and the dependent variables. Model fit decreased after adding covariates, possibly because the introduction of new parameters lead to a reduction of statistical power and because the covariates may not correspond well with the data, as shown by the many insignificant pathways between covariates and outcome variables. The $\chi^{2} / \mathrm{df}$ and RMSEA fit indices were still satisfactory (see Table 5, Final multilevel model). We settled on this model as our final model.

Figure 3 presents a visual summary of the final multilevel model including unstandardized parameter estimates and standard errors. In this model, Oral Language Teaching covaried with Oral Language Exposure and with Code Activities, while Code Activities did not covary with Oral Language Exposure, implying that parents who engage in Oral Language Teaching also engage in Oral Language Exposure and Code Activities, but that parents engaging in Oral Language Exposure 


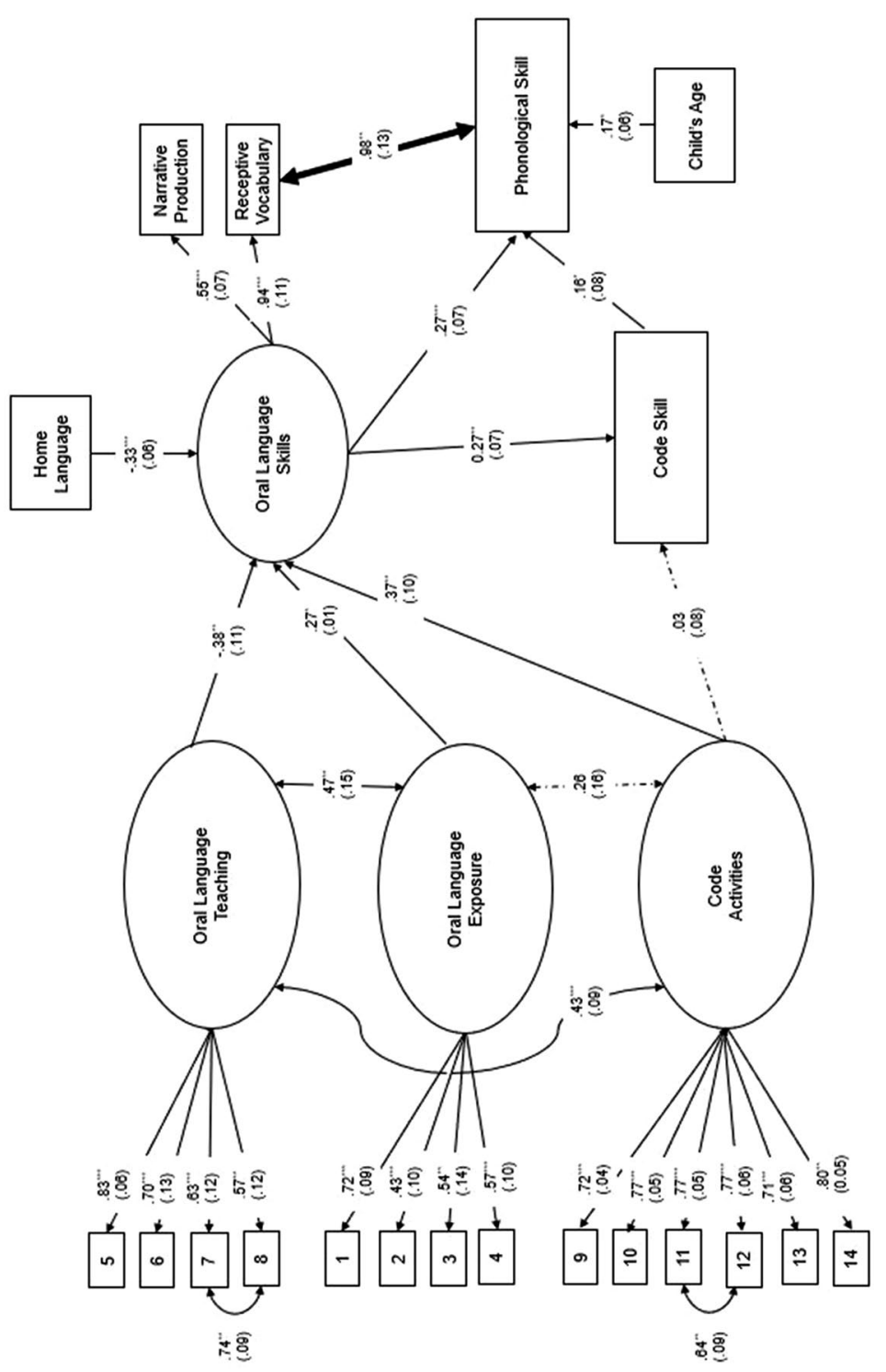

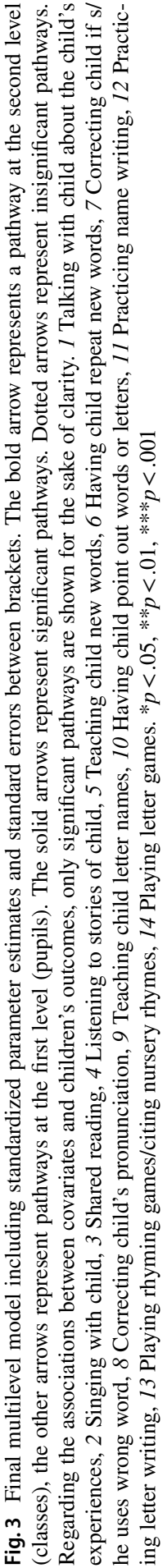


do not necessarily engage in Code Activities. All home activities were associated with Oral Language, but the pathway from Oral Language Teaching to Oral Language was negative. Oral Language was related to letter-sound knowledge. An additional analysis showed that Oral Language partially mediated the pathway from Code Activities to letter knowledge: the indirect effect was statistically significant $(\beta=0.432$ [0.163], $t=2.651, p<0.01)$. Both Oral Language and letter-sound knowledge were associated with phonological skill. At the class level, vocabulary covaried with phonological skill. The final model explained $36 \%$ of the variance in children's oral language skills, $8 \%$ of the variance in children's letter-sound knowledge, and $20 \%$ of the variance in children's phonological skill.

\section{Discussion}

The purpose of this study was to explore a refined model of home literacy activities and their relations with children's emergent literacy skills, using the Home Literacy Model (HLM) as a starting point (Sénéchal, 2006; Sénéchal \& LeFevre, 2002). First, we investigated the validity of a conceptualization of home literacy activities based on two variables: targeted skills (oral language/code) and didactic approach (exposure/teaching). We found evidence for three activity categories. Home literacy activities were classified according to the skills targeted by the activity, resulting in activities targeting code skills and activities targeting oral language skills. Oral language activities were further divided into activities adopting a teaching method, such as teaching the meaning of new words, and an exposure approach, such as shared reading. Second, relations between the different types of home literacy activities resulting from this conceptualization and children's early language and literacy skills were explored. All types of home literacy activities (including code activities) were related to children's oral language skills, although the association between oral language teaching activities and oral language skills was negative. In turn, oral language skills were related to children's letter-sound knowledge and phonological skill, supporting evidence for the vital role of oral language in young children's emergent literacy development (Storch \& Whitehurst, 2002; Whitehurst \& Lonigan, 1998). Besides oral language skills, also letter-sound knowledge was associated with phonological skill, in accordance with the HLM.

The findings show that a broader range of activities than defined by the original HLM is associated with children's emergent literacy skills. First, also non-print activities, such as talking with children about the child's experiences and singing songs, appear to fit in a framework of activities that contribute to emergent literacy skills. Second, while nearly all previous operationalizations of formal literacy activities only included teaching activities (e.g., teaching of letter names), code activities in the refined model included activities that are more informal as well, such as playing letter games. The absence of the expected distinction in code activities between exposure and teaching may be explained by the low levels of code skill for the children in our sample (which is also the case in several of the previous HLM studies, e.g. Carroll, 2013; Kim, 2009; Manolitsis et al., 2011, 2013; Sénéchal \& 
LeFevre, 2014; Sparks \& Reese, 2012). Participating in playful code-activities such as playing letter games might still imply a substantial amount of parental teaching if the child's letter-sound knowledge is very limited. Third, including the didactic aspect in conceptualizing home literacy activities resulted in a new type of activities, namely those targeting oral language skills through teaching, for example by teaching children new words.

The association between oral language teaching activities and children's oral language skills was negative. Although the cross-sectional research design does not allow any causal interpretations of this association, we propose two possible mechanisms that might be operational in our sample and that may be tested in future research, for instance through longitudinal studies. First, parents might adjust their teaching behavior to their children's performance, implying that if children underperform in oral language and literacy, parents increase their teaching activities in the home (Kim, 2009; Manolitsis et al., 2011; Sénéchal \& LeFevre, 2014; Silinskas et al., 2013). Second, oral language teaching activities may be indicative of an interaction style that does not contribute to language development. According to interactionist perspectives on language acquisition, children best acquire oral language in an environment that allows them to actively interact with adults, responding to positive feedback provided by the adult (Chapman, 2000; Lonigan \& Whitehurst, 1998). Whereas exposure activities such as shared reading and parent-child conversations may create the circumstances for oral language learning to occur, the direct teaching of oral language skills may restrict children's opportunities to contribute to the interaction. As such, oral language teaching activities possibly limit children's oral language development as they render the children passive.

In agreement with informal activities in the original HLM, oral language exposure activities were positively related to children's oral language skills. For code activities, the outcomes were different than predicted by the HLM. Contrary to studies in English and French speaking families (cf. Sénéchal \& Lefevre, 2002; 2014; Skwarchuk et al., 2014), code activities were not significantly related to children's code skill. Compared to English and French, Dutch has a transparent orthography. As the Dutch code is relatively easy to master, parental teaching of code skills might not significantly add up to the input the child already receives in kindergarten (see also Manolitsis et al., 2011). Furthermore, the association between code activities and children's code skill (letter-sound knowledge) was mediated by oral language skills. This implies the presence of two other unexpected effects, namely a direct effect of code activities on oral language skills and a direct effect of oral language skills on letter-sound knowledge.

One explanation for the observed association between code activities and oral language is that we used a broadened construct of code activities, including the nonteaching activities rhyming and playing letter games. To test whether this choice had affected our outcomes, we ran the model without these two items. This did not change any of the pathways, supporting the coherence of the construct. The association found between code activities and oral language skills might rather be explained by the nature of the interaction during these activities. Likely, engaging in code activities exposes children to richer language input: teaching about letters and print might additionally imply increased parental vocabulary use. In ABC books 
for instance, letters are connected to word meanings, by showing a letter combined with a picture of a word starting with that letter (for example, the T of tree, the P of pajamas). A similar observation was made by Haney and Hill (2004), who found a relationship between the teaching of letters and children's oral language skills.

The association between oral language skills and letter-sound knowledge is in line with previous research that has shown that especially in younger children the relation between oral language and decoding skills is strong and only declines after children have started formal schooling (Kendeou et al., 2009; Storch \& Whitehurst, 2002). Children, particularly this young of age, may be dependent on their Dutch oral language skills to process any teaching and other input regarding letters and decoding skills (NICHD, 2005). This may be especially true for second language learners of Dutch, who represented a large part of the sample. Also, children might remember letters more easily, when they can connect them to word meanings, thus applying oral language skills. Another possible explanation for the association between oral language skills and letter-sound knowledge is that letter names can be regarded as vocabulary items. Children with larger vocabularies acquire new words more easily (Verhoeven, Van Leeuwe, \& Vermeer, 2011).

Due to nesting in the data (pupils within classes) this study applied a multilevel approach. This implied we also considered pathways at the class level. In this study, a covariation between vocabulary and phonological skill at class level was observed. Little is known on the interrelationships between emergent literacy outcomes at class levels, as research in the field does not always consider the nested nature of the data. The observation that class averages on the vocabulary measure covary with class averages on phonological skill may be a demographic effect. Our sample contained many second language learners for whom both Dutch vocabulary and Dutch phonology are relatively new compared to monolingual Dutch pupils. Children with stronger vocabulary skills often have stronger phonological skills. Possibly, second language learners were clustered in classes and monolingual pupils were clustered in classes. Additionally, especially in classes with many second language learners, vocabulary teaching and a focus on phonology may go hand in hand, for example by focusing both on meaning and sound in singing and rhyming activities.

While most studies confirming the HLM were conducted with samples of monolingual middle-class Anglo-Saxon children (cf. Hood et al., 2008; Skwarchuk et al., 2014), a strength of the current study is the sample of children with diverse backgrounds regarding parental education and home language, in the context of urban parts of the Netherlands. To date, the HLM has not been investigated in such a context. Most research into the HLM is conducted in homogenous samples regarding children's demographic characteristics. In urbanized parts of the Netherlands, people with all kinds of backgrounds cohabit. In their daily practice, teachers deal with highly diverse groups of children regarding the socio-economic, educational, and linguistic background of their families. In this setting, including this diversity in the sample seems to be a more ecologically valid choice.

Although we entered demographic background variables as covariates in our final model, differences between the original HLM and the refined model in this study may be explained by the specific context of this study. To find further explanations for differences between the pathways reported in the original HLM and our refined 
model, we explored correlations between demographic background factors and the three home literacy activity factors (using weighted means calculated from the factor loadings). Home language was significantly negatively correlated with oral language exposure ( $r=-.18$ ), implying that multilingual families engaged less frequently in this kind of activities than monolingual Dutch parents, which may be an indication of cultural differences in home practices supporting children's emergent literacy development. Children's age was negatively related to oral language teaching activities, indicating that parents of older children were less likely to directly teach their children about language than younger children. No other significant correlations between demographic background variables and the home literacy activity factors were found. To provide further insight into how demographic aspects may influence pathways between home literacy activities and children's emergent literacy outcomes, future research on the HLM in diverse samples is necessary.

\section{Limitations and directions for future research}

A first limitation of this study concerns the model fit. Although fit was good regarding $\chi^{2} / \mathrm{df}$ and RMSEA, the CFI-value and SRMR measures were suboptimal. This requires modesty in approaching the results. This exploratory study must therefore be regarded as a first step in defining a more inclusive and nuanced model of home literacy activities and emergent literacy outcomes, but the model needs further validation in future studies. Another limitation is the cross-sectional design of the study, which precludes any causal statements regarding the relation between home literacy activities and children's literacy skills. Additionally, we did not include the child's perspective in this study, although the child's behavior may have influenced parental home literacy behavior. A third limitation of this study is that the data do not provide any information in which language parents performed the home literacy activities investigated as this was not included in our questionnaire. As such, we cannot make any statements concerning the advantages or disadvantages of performing home literacy activities in the first or second language for children's emergent literacy development in Dutch. Additionally, although we put much effort in accommodating all parents, we cannot exclude the possibility that some parents could not interpret the questionnaires due to limited proficiency in Dutch or limited literacy skills. A final limitation is the possibility of social desirability given the parent self-report data. Social desirability may partly explain the relatively low correlations between questionnaire items and child outcomes, because it may have limited the variation in parent responses on the questionnaire.

Future research, using larger samples and longitudinal designs, is needed to confirm our exploratory model. The latter would also allow analyzing the long-term relations between different types of home literacy activities and children's more advanced reading skills, such as word decoding, reading fluency, and text comprehension (Sénéchal, 2006; Sénéchal \& LeFevre, 2014). Since we tested the model in a heterogeneous sample, it would be interesting to examine whether the structure we obtained holds in a more homogeneous sample (e.g., a sample of mainly higher educated parents, native parents, or monolingual parents), also because previous studies 
on the HLM were often limited to such samples. Furthermore, the current research suggests that participation in a wide range of both code and oral language exposure activities at home may be beneficial for children's emergent literacy development, through its contribution to oral language skills. Although experimental research exists on the impact of code-oriented approaches versus oral language approaches in center-based settings (Lonigan et al., 2013), the Home Literacy Model and the refined model proposed in this study have not yet been investigated in experimental designs. Family literacy programs focusing on either code-activities, oral language exposure activities, or oral language teaching activities at home could be designed and implemented to experimentally investigate the unique impact of different types of home literacy activities on children's emergent literacy skills. This type of research could offer more solid foundations for the relations described in this study.

As mentioned previously, the HLM is hardly investigated in heterogeneous samples of families. Future research should consider diversity, especially when this diversity is part of the context in which the study is conducted, which was the case in the current study. Existing research has shown that the literacy development of children with different linguistic, cultural and socio-economic backgrounds varies and that parents' roles in children's literacy development is associated with these backgrounds (Hart \& Risley, 1995; Hoff, 2013; Scheele, Leseman, \& Mayo, 2010; Van Steensel, 2006). Indeed, studies investigating the HLM using different types of samples regarding SES, linguistic and cultural backgrounds often found deviant results (Kalia \& Reese, 2009; Kim, 2009; Manolitsis et al., 2011; Sparks \& Reese, 2012). However, the current study did not specifically examine the role such background characteristics might play in explaining differences in interrelations between components of the HLM. Examining such differences applying multi-group analyses could be the subject of future research. Additionally, future research with multilingual families could specifically focus on the role of home language in home activities for both first and second language development.

\section{Conclusion}

This study explored a refined model of home literacy activities and their relations with children's emergent literacy skills. The results indicate that a broader definition of home literacy activities including non-print activities is suitable to describe children's home literacy experiences. By additionally considering didactic approach in the model, we identified a new category of home literacy activities, namely oral language teaching. The refined model of home literacy activities offered in this study enables researchers to describe differences in children's home literacy experiences more accurately. The outcomes suggest the existence of a more nuanced pattern of interrelations between elements of the home literacy environment and children's literacy skills in a diverse sample of families.

Acknowledgements Funding was provided by Nationaal Regieorgaan Onderwijsonderzoek (Grant No. 405-14-571). 
Open Access This article is distributed under the terms of the Creative Commons Attribution 4.0 International License (http://creativecommons.org/licenses/by/4.0/), which permits unrestricted use, distribution, and reproduction in any medium, provided you give appropriate credit to the original author(s) and the source, provide a link to the Creative Commons license, and indicate if changes were made.

\section{References}

Aarnoutse, C., \& Verhagen, W. (2012). Handleiding en scoringsformulieren nieuwe toetsen Toetspakket Beginnende geletterdheid. [Manual and score forms new tests Test Battery Emergent Literacy]. Amersfoort: CPS.

Anthony, J. L., Lonigan, C. J., Driscoll, K., Phillips, B. M., \& Burgess, S. R. (2003). Phonological sensitivity: A quasi-parallel progression of word structure units and cognitive operations. Reading Research Quarterly, 38(4), 470-487. https://doi.org/10.1598/RRQ.38.4.3.

Brown, T. A. (2006). Confirmatory factor analysis for applied research. New York: Guilford Publications.

Burgess, S. R., Hecht, S. A., \& Lonigan, C. J. (2002). Relations of the home literacy environment (HLE) to the development of reading-related abilities: A one-year longitudinal study. Reading Research Quarterly, 37, 408-426. https://doi.org/10.1598/RRQ.37.4.4.

Byrne, B. M. (2012). Structural equation modeling with Mplus: Basic concepts, applications, and programming. New York: Routledge.

Cárdenas-Hagan, E., Carlson, C. D., \& Pollard-Durodola, S. D. (2007). The cross-linguistic transfer of early literacy skills: The role of initial L1 and L2 skills and language of instruction. Language, speech, and hearing services in schools, 38(3), 249-259.

Carroll, C. (2013). The effects of parental literacy involvement and child reading interest on the development of emergent literacy skills. Doctoral dissertation, UW-Milwaukee. Retrieved on May 22, 2019 from http://dc.uwm.edu/etd/230/.

Chapman, R. S. (2000). Children's language learning: An interactionist perspective. The Journal of Child Psychology and Psychiatry and Allied Disciplines, 41(1), 33-54. https://doi.org/10.1111/14697610.00548.

Chen, X., Zhou, H., Zhao, J., \& Davey, G. (2010). Home literacy experiences and literacy acquisition among children in Guangzhou, South China. Psychological Reports, 107(2), 354-366. https://doi. org/10.2466/04.11.17.21.28.pr0.107.5.354-366.

Curenton, S. M., Craig, M. J., \& Flanigan, N. (2008). Use of decontextualized talk across story contexts: How oral storytelling and emergent reading can scaffold children's development. Early Education and Development, 19(1), 161-187. https://doi.org/10.1080/10409280701839296.

Dickinson, D. K., McCabe, A., Anastasopoulos, L., Peisner-Feinberg, E. S., \& Poe, M. D. (2003). The comprehensive language approach to early literacy: The interrelationships among vocabulary, phonological sensitivity, and print knowledge among preschool-aged children. Journal of Educational Psychology, 95(3), 465-481. https://doi.org/10.1037/0022-0663.95.3.465.

Dixon, L. Q. (2011). The role of home and school factors in predicting English vocabulary among bilingual kindergarten children in Singapore. Applied Psycholinguistics, 32(1), 141-168.

Gillanders, C., \& Jiménez, R. T. (2004). Reaching for success: A close-up of Mexican immigrant parents in the USA who foster literacy success for their kindergarten children. Journal of Early Childhood Literacy, 4(3), 243-269. https://doi.org/10.1177/1468798404044513.

Haney, M., \& Hill, J. (2004). Relationships between parent-teaching activities and emergent literacy in preschool children. Early Child Development and Care, 174, 215-228. https://doi. org/10.1080/0300443032000153543.

Hannon, P. (2000). Reflecting on literacy education. London: RoutledgeFalmer.

Hannon, P. (2003). Family literacy programmes. In N. Hall, J. Larson, \& J. Marsh (Eds.), Early childhood literacy (pp. 99-111). London: SagePublications Ltd.

Hart, B., \& Risley, T. R. (1995). Meaningful differences in the everyday experience of young American children. Baltimore: Paul H. Brookes Publishing.

Hoff, E. (2006). How social contexts support and shape language development. Developmental Review, 26(1), 55-88. https://doi.org/10.1016/j.dr.2005.11.002. 
Hoff, E. (2013). Interpreting the early language trajectories of children from low-SES and language minority homes: Implications for closing achievement gaps. Developmental Psychology, 49(1), 4-14. https://doi.org/10.1037/a0027238.

Hood, M., Conlon, E., \& Andrews, G. (2008). Preschool home literacy practices and children's literacy development: A longitudinal analysis. Journal of Educational Psychology, 100(2), 252-271. https:// doi.org/10.1037/0022-0663.100.2.252.

Hoover, W. A., \& Gough, P. B. (1990). The simple view of reading. Reading and Writing, 2(2), 127-160. https://doi.org/10.1007/BF00401799.

Hox, J. J. (2010). Multilevel analysis: Techniques and applications. New York: Routledge.

Hu, L. T., \& Bentler, P. M. (1999). Cutoff criteria for fit indexes in covariance structure analysis: Conventional criteria versus new alternatives. Structural Equation Modeling: A Multidisciplinary Journal, 6(1), 1-55. https://doi.org/10.1080/10705519909540118.

Janssen, C., Segers, E., McQueen, J. M., \& Verhoeven, L. (2017). Transfer from implicit to explicit phonological abilities in first and second language learners. Bilingualism: Language and Cognition, 20(4), 795-812. https://doi.org/10.1017/s1366728916000523.

Kalia, V., \& Reese, E. (2009). Relations between Indian children's home literacy environment and their English oral language and literacy skills. Scientific Studies of Reading, 13(2), 122-145. https://doi. org/10.1080/10888430902769517.

Kendeou, P., Van den Broek, P., White, M. J., \& Lynch, J. S. (2009). Predicting reading comprehension in early elementary school: The independent contributions of oral language and decoding skills. Journal of Educational Psychology, 101(4), 765-778. https://doi.org/10.1037/a0015956.

Kim, Y. S. (2009). The relationship between home literacy practices and developmental trajectories of emergent literacy and conventional literacy skills for Korean children. Reading and Writing, 22, 57-84. https://doi.org/10.1007/s11145-007-9103-9.

Kline, R. B. (2015). Principles and practice of structural equation modeling (4th ed.). New York: The Guilford Press.

Levy, B. A., Gong, Z., Hessels, S., Evans, M. A., \& Jared, D. (2006). Understanding print: Early reading development and the contributions of home literacy experiences. Journal of Experimental Child Psychology, 93(1), 63-93. https://doi.org/10.1016/j.jecp.2005.07.003.

Lonigan, C. J., Purpura, D. J., Wilson, S. B., Walker, P. M., \& Clancy-Menchetti, J. (2013). Evaluating the components of an emergent literacy intervention for preschool children at risk for reading difficulties. Journal of Experimental Child Psychology, 114(1), 111-130. https://doi.org/10.1016/j. jecp.2012.08.010.

Lonigan, C. J., \& Whitehurst, G. J. (1998). Relative efficacy of parent and teacher involvement in a shared-reading intervention for preschool children from low-income backgrounds. Early Childhood Research Quarterly, 13, 263-290. https://doi.org/10.1016/S0885-2006(99)80038-6.

Lynch, J., Anderson, J., Anderson, A., \& Shapiro, J. (2006). Parents' beliefs about young children's literacy development and parents' literacy behaviors. Reading Psychology, 27(1), 1-20. https://doi. org/10.1080/02702710500468708.

Manolitsis, G., Georgiou, G. K., \& Parrila, R. (2011). Revisiting the home literacy model of reading development in an orthographically consistent language. Learning and Instruction, 21, 496-505. https://doi.org/10.1016/j.learninstruc.2010.06.005.

Manolitsis, G., Georgiou, G. K., \& Tziraki, N. (2013). Examining the effects of home literacy and numeracy environment on early reading and math acquisition. Early Childhood Research Quarterly, 28(4), 692-703. https://doi.org/10.1016/j.ecresq.2013.05.004.

Manolitsis, G., Georgiou, G., Stephenson, K., \& Parrila, R. (2009). Beginning to read across languages varying in orthographic consistency: Comparing the effects of non-cognitive and cognitive predictors. Learning and Instruction, 19(6), 466-480. https://doi.org/10.1016/j.learninstruc.2008.07.003.

McBride-Chang, C. (1995). What is phonological awareness? Journal of Educational Psychology, 87(2), 179. https://doi.org/10.1037/0022-0663.87.2.179.

Muthén, L. K., \& Muthén, B.O. (1998-2010). Mplus user's guide (6th edition). Los Angeles, CA: Muthén \& Muthén. Retrieved on May 22, 2019, from https://www.statmodel.com/download/users guide/Mplus\%20Users\%20Guide\%20v6.pdf.

NICHD Early Child Care Research Network. (2005). Pathways to reading: The role of oral language in the transition to reading. Developmental Psychology, 41(2), 428-442. https://doi. org/10.1037/0012-1649.41.2.428.

Niklas, F., \& Schneider, W. (2013). Home literacy environment and the beginning of reading and spelling. Contemporary Educational Psychology, 38, 40-50. https://doi.org/10.1016/j.cedpsych.2012.10.001. 
Raudenbush, S., Bryk, A., Cheong, Y., Congdon, R., \& Du Toit, M. (2016). HLM7 Hierarchical linear and nonlinear modeling user manual: user guide for scientific software international's (S.S.I.) program. Skokie, IL: Scientific Software International, Incorporated.

Reese, L., Arauz, R. M., \& Bazán, A. R. (2012). Mexican parents' and teachers' literacy perspectives and practices: construction of cultural capital. International Journal of Qualitative Studies in Education, 25(8), 983-1003. https://doi.org/10.1080/09518398.2011.594818.

Reese, L., \& Gallimore, R. (2000). Immigrant Latinos' cultural model of literacy development: An evolving perspective on home-school discontinuities. American Journal of Education, 108(2), 103-134. https://doi.org/10.1086/444236.

Satorra, A., \& Bentler, P. M. (2001). A scaled difference Chi square test statistic for moment structure analysis. Psychometrika, 66, 507-514. https://doi.org/10.1007/BF02296192.

Scheele, A. F., Leseman, P. P., \& Mayo, A. Y. (2010). The home language environment of monolingual and bilingual children and their language proficiency. Applied Psycholinguistics, 31(1), 117-140. https://doi.org/10.1017/S0142716409990191.

Schermelleh-Engel, K., Moosbrugger, H., \& Müller, H. (2003). Evaluating the fit of structural equation models: Tests of significance and descriptive goodness-of-fit measures. Methods of Psychological Research Online, 8(2), 23-74. https://doi.org/10.3389/fpsyg.2014.00181.

Sénéchal, M. (2006). Testing the home literacy model: Parent involvement in kindergarten is differentially related to grade 4 reading comprehension, fluency, spelling, and reading for pleasure. Scientific Studies of Reading, 10(1), 59-87. https://doi.org/10.1207/s1532799xssr1001_4.

Sénéchal, M., \& LeFevre, J. (2002). Parental involvement in the development of children's reading skill: A five-year longitudinal study. Child Development, 73(2), 445-460. https://doi.org/10.1111/14678624.00417.

Sénéchal, M., \& LeFevre, J. (2014). Continuity and change in the home literacy environment as predictors of growth in vocabulary and reading. Child Development, 85(4), 1552-1568. https://doi. org/10.1111/cdev.12222.

Sénéchal, M., LeFevre, J. A., Smith-Chant, B., \& Colton, K. V. (2001). On refining theoretical models of emergent literacy the role of empirical evidence. Journal of School Psychology, 39, 439-460. https ://doi.org/10.1016/S0022-4405(01)00081-4.

Sénéchal, M., Whissell, J., \& Bildfell, A. (2017). Starting from home: Home literacy practices that make a difference. In K. Cain, D. Compton, \& R. Parrila (Eds.), Theories of reading development (pp. 383-408). Amsterdam, The Netherlands: John Benjamins.

Silinskas, G., Kiuru, N., Tolvanen, A., Niemi, P., Lerkkanen, M., \& Nurmi, J. (2013). Maternal teaching of reading and children's reading skills in grade 1: Patterns and predictors of positive and negative associations. Learning and Individual Differences, 27, 54-66. https://doi.org/10.1016/j.lindi f.2013.06.011.

Silinskas, G., Leppänen, U., Aunola, K., Parrila, R., \& Nurmi, J. E. (2010). Predictors of mothers' and fathers' teaching of reading and mathematics during kindergarten and Grade 1. Learning and Instruction, 20(1), 61-71. https://doi.org/10.1016/j.learninstruc.2009.01.002.

Silinskas, G., Lerkkanen, M. K., Tolvanen, A., Niemi, P., Poikkeus, A. M., \& Nurmi, J. E. (2012). The frequency of parents' reading-related activities at home and children's reading skills during kindergarten and Grade 1. Journal of Applied Developmental Psychology, 33(6), 302-310. https://doi. org/10.1016/j.appdev.2012.07.004.

Skwarchuk, S. L., Sowinski, C., \& LeFevre, J. A. (2014). Formal and informal home learning activities in relation to children's early numeracy and literacy skills: The development of a home numeracy model. Journal of Experimental Child Psychology, 121, 63-84. https://doi.org/10.1016/j. jecp.2013.11.006.

Sociaal Cultureel Planbureau [Netherlands Institute for Social Research]. (2017). Statusscores [Data file]. Retrieved on May 22, 2019, from https://www.scp.nl/Onderzoek/Lopend_onderzoek/A_Z_alle_ lopende_onderzoeken/Statusscores.

Sparks, A., \& Reese, E. (2012). From reminiscing to reading: Home contributions to children's developing language and literacy in low-income families. First Language, 33, 89-109. https://doi. org/10.1177/0142723711433583.

Statistics Netherlands. (2017). Population; educational level; gender, age and migration background [Database]. Retrieved on May 22, 2019, from http://statline.cbs.nl/StatWeb/publicatio $\mathrm{n} /$ ?VW=T\&DM=SLNL\&PA=82275NED\&LA=NL. 
Stephenson, K. A., Parrila, R. K., Georgiou, G. K., \& Kirby, J. R. (2008). Effects of home literacy, parents' beliefs, and children's task-focused behavior on emergent literacy and word reading skills. Scientific Studies of Reading, 12(1), 24-50. https://doi.org/10.1080/10888430701746864.

Stichting Leerplan Ontwikkeling [Institute for Curriculum Development]. (2010). Taalontwikkeling van het jonge kind: de doelen [Language Development of Young Pupils: The Goals]. Enschede, The Netherlands: Institute for Curriculum Development.

Stipek, D., Milburn, S., Clements, D., \& Daniels, D. H. (1992). Parents' beliefs about appropriate education for young children. Journal of Applied Developmental Psychology, 13(3), 293-310. https://doi. org/10.1016/0193-3973(92)90034-f.

Storch, S. A., \& Whitehurst, G. J. (2002). Oral language and code-related precursors to reading: Evidence from a longitudinal structural model. Developmental Psychology, 38(6), 934-947. https://doi. org/10.1037/0012-1649.38.6.934.

Van Steensel, R. (2006). Relations between socio-cultural factors, the home literacy environment and children's literacy development in the first years of primary education. Journal of Research in Reading, 29(4), 367-382. https://doi.org/10.1111/j.1467-9817.2006.00301.x.

Verhoeven, L., van Leeuwe, J., \& Vermeer, A. (2011). Vocabulary growth and reading development across the elementary school years. Scientific Studies of Reading, 15(1), 8-25.

Verhoeven, L., \& Vermeer, A. (2001). Taaltoets Alle Kinderen. Diagnostische toets voor de mondelinge vaardigheid Nederlands bij kinderen van groep 1 tot en met 4. [Language Test for All Children. Diagnostic test for Dutch oral language skills for children in kindergarten until grade 2]. Arnhem: Centraal Instituut voor Toetsontwikkeling.

Verhoeven, L., \& Vermeer, A. (2006). Verantwoording Taaltoets Alle Kinderen (TAK). [Justification Language Test for All Children]. Arnhem: Centraal Instituut voor Toetsontwikkeling. Retrieved on May 22, 2019, from https://www.researchgate.net/publication/239843705_Verantwoording_Taaltoets_ Alle_Kinderen_TAK/download.

Weigel, D. J., Martin, S. S., \& Bennett, K. K. (2006). Mothers' literacy beliefs: Connections with the home literacy environment and pre-school children's literacy development. Journal of Early Childhood Literacy, 6, 191-211. https://doi.org/10.1177/1468798406066444.

Whitehurst, G. J., \& Lonigan, C. J. (1998). Child development and emergent literacy. Child Development, 69(3), 848-872. https://doi.org/10.1111/j.1467-8624.1998.tb06247.x.

Publisher's Note Springer Nature remains neutral with regard to jurisdictional claims in published maps and institutional affiliations. 